\title{
Psycho Social Factors Influencing Youth Alcoholism at Agogo, Ghana
}

\author{
Samuel Owusu-Akyem \\ Head of Department, Department of Nursing, Presbyterian University College, Ghana
}

\begin{abstract}
This study explored psychosocialfactors influencing youth alcoholism at Agogo, Ghana,using a qualitative approach where in-depth interview techniques were employed. A total of 12 youth from the Substance Abuse Unit at Agogo Hospital were interviewed. Results: included peer pressure, youthunemployment and poverty, inadequate knowledge of the effect of alcoholism, absence of youth alcoholics support group, absence of leisure and boredom. Recommendations based on the findings included;massive education on effects of alcoholism in the media, hospitals and homes by Ministry of Health (MOH), Ghana Health Service (GHS) and health professionals; making clear the position of $\mathrm{MOH}$ on policies on the risk and the dangers that pose to the youth in Ghana.Hospitals to create peer counseling unittomanage peer pressures.Metropolitan, Municipal and District Assemblies to create some form of employment through youth training schemes and leisure centres to deal with boredom and youth unemployment.The government should come out with policies and programmes to support the youth to manage poverty. Finally, a strong rehabilitation and counselingcentres should also be established by the government and other non-governmental organisations to manage alcoholism.
\end{abstract}

Keywords: Youth Alcoholism, Psychosocial Factors, Influence

\section{Introduction}

Every day, on average, 11,318 American youth (12 to 20 years of age) try alcohol for the first time, compared with 6,488 for marijuana; 2,786 for cocaine; and 386 for heroin. (Myadze\&Rwomire, 2014). Globally, alcohol use causes 1.8 million or $3.2 \%$ of all deaths and accounts for $4.0 \%$ of the disease burden. (Benegal, et al. 2007) The disease burden related to alcohol use is especially great among low income and middle-income populations and countries, where alcohol consumption is increasing and injury rates are high due to limited implementation of public health policies and prevention strategies. (Rehm, et al. 2009; Benegal, et al. 2007). The World Health Organization (2001) estimates that there are over 140 million people who suffer from alcoholism worldwide. (Mayor, 2001). In the EU in 2004, alcohol was responsible for 1 in 7 male deaths and 1 in 13 female deaths in the group aged 15-64 years, resulting in approximately 120000 premature deaths. The most recent data collected from Member States, based on recorded consumption in 2010 and presented in this report, show that adults (age 15+ years) in the EU (including in Croatia) drink 10litres of pure alcohol per year (recorded consumption only). When Norway, Switzerland and the candidate countries are included, the figure is 9 litres of pure alcohol per capital. (WHO, 2013)

According to Ghana Health Foundation (2006) scientist do not know exactly what causes alcoholism but most experts suspect that a combination of physiological, environmental and psychological factors are involved. In Ghanaian society, like any other society, people take alcohol in certain occasions and for various reasons at social gatherings, marriage ceremonies, parties, outdooring and funerals. Others take in alcohol to manage their problems, whiles others take in alcohol to enhance their working performance. According to Alcoholics Anonymous UK excessive use of alcohol causes liver disorders, nausea, vomiting, anorexia, muscular incoordination, poor judgment and clammy skin. It can also lead to sexual dysfunction, menstruation problems, cardiovascular problems, neurological complications, congenital effects and death. Domestic abuse, divorce, poor performance at work, loss of self-esteem, disrespect, selfembarrassment in public places and higher incidence of suicide and murder are some of the socio-economic effects of alcoholism (Langdana, 2009). Although there have been some research on effects of alcoholism by other researchers, little has been published on psychosocial factors influencing youth alcoholism in Ghana. Hence, the current study explored psychosocial factors that influence youth alcoholism in Agogo, Ghana using a qualitative approach. This study was conducted at Agogo in the Asante Akyem North District. It is particularly important since the District Health Directorate of Asante Akyem North reported in 2013 that the youth of Agogo have taken to excessive alcohol consumption, which is affecting their health negatively. The health authorities in the District are seriously concerned of the health consequences of the youth Agogo is located in the Ashanti Region of Ghana, the second most populous region in Ghana, according to Ghana Statistics Authority (2010). The people mostly farmers, indulge in subsistence farming and the percentage of the population living in poverty is as high as $68 \%$. The key question then is whether poverty, peer pressure and unemployment are causing the youth in this community to take to alcoholism. In particular the current study answers the question as to what psychosocial factors influence youth alcoholism in this community.

\subsection{Objective}

To explore psychosocial factors influencing youth alcoholism at Agogo, Ghana.

\subsection{Significance of the Study}

The study will contribute to enhance various management and existing educational programmes on alcohol abuse among the youth. The findings will assist in shaping policies on alcohol abuse by the healthcare professionals and other policy makers. Furthermore, the study recommendations if implemented effectively can also assist the youth to address 


\section{International Journal of Science and Research (IJSR) \\ ISSN (Online): 2319-7064 \\ Index Copernicus Value (2013): 6.14 | Impact Factor (2014): 5.611}

factors that will help them to abstain from alcoholism or reduce alcohol consumption. Finally, the study will provide impetus for further research into the area of youth alcoholism.

\section{Literature Survey}

World trends in alcohol consumption rose steeply during the several decades preceding the 1980s. Data collected from 97 countries revealed that between 1960 and 1972 alcohol production rose by more than $60 \%$. Regions with the highest level of economic development tend to have the highest per capita consumption of alcohol. In western countries the upsurge in alcohol production is attributed to the rising prevalence of social drinking and the highly industrialized production of alcohol. The World Health Organization (WHO) estimated that during the late twentieth century there were 140 million people in the world who were alcohol dependent (Mayor, 2001). Generally, it has been found out that men are more likely to drink than women with the estimate of $68 \%$ for men and $54 \%$ for women and men also drink more frequently than women (Harker, 2012)

According to Uganda Youth Development Link (2008), the harmful use of alcohol causes considerable public health problems and is ranked as the fifth leading risk factor in premature death and disability in the world. In 2002, approximately 2,300,000 people died worldwide from alcohol-related causes and about 64,975,000 disability adjusted life years (Daly's) were lost due to alcohol causes. The global economic cost of the harmful use of alcohol in 2002 (in US dollars) was estimated at between 210,000 million and 665,000 million: Illness: 50,000 - 120,000, Premature mortality: 55,000 - 210,000 million, Drinkdriving: 30,000 - 55,000 million, Absenteeism: 30,000 65,000 million, Unemployment: 80,000 million, Criminal justice: 30,000 - 85,000 million, Criminal damage: 15,000 50,000 million. The total cost of alcohol equates to between $0.6 \%$ and $2.0 \%$ of the global gross domestic product. Alcohol abuse has disastrous consequences. A World Health Organisation (WHO) report indicates that $10 \%$ to $69 \%$ of suicides are committed annually under the influence of alcohol and between $5-10 \%$ of parents abusing their children have alcohol use disorders.

Despite all these problems, the harmful use of alcohol remains a low priority in public policy, including in health policy. Many lesser health risks have higher priority. The harmful use of alcohol is a particularly grave threat to men. It is the leading risk factor for death in males ages 15-59, mainly due to injuries, violence and cardiovascular diseases. Globally, 6.2\% of all male deaths are attributable to alcohol, compared to $1.1 \%$ of female deaths. Men also have far greater rates of total burden attributed to alcohol than women $-7.4 \%$ for men compared to $1.4 \%$ for women. Men outnumber women four to one in weekly episodes of heavy drinking - most probably the reason for their higher death and disability rates. Men also have much lower rates of abstinence compared to women. Lower socio-economic status and educational levels result in a greater risk of alcohol-related death, disease and injury - a social determinant that is greater for men than women. (WHO, 2011)

Chassin et al (1996) have attributed alcohol use in early adolescence to the social, family and environmental factors. Many possible factors can lead to alcohol use and abuse. Among those factors are social and psychological issues (Freeman \& Parry, 2006). Even though there are significant studies conducted on related factors that lead to Alcohol use, abuse, and alcoholism (Freeman \& Parry, 2006; Finger, et al. \& Leonard, 2010; Donovan,2004) there are not enough studies conducted about psychosocial factors causing alcohol abuse/dependency (Al-Marri\&Oei,2009; Al-Haqwi, 2010). The strongest and most researched correlate of adolescent alcohol abuse is peer pressure (White and Jackson, 2005). Laurie (2001) stated that alcohol impairs both mental and motor functions including hand-eye coordination. Other studies have examined various personal characteristics that contribute to the likelihood of alcohol use and abuse. Alcohol initiation usually occurs in early adolescence with an increase in consumption throughout adolescence and early adulthood followed by a gradual decrease over the following years (Duncan et al. 1998; Hughes et al.1997; Hussong and Chassin 1997). Adolescence is recognized as a phase of alcohol experimentation (Beck et al. 1993).

Duncan et al (1998) indicated that the quantity of alcohol consumption is higher among lower income households, although those in higher income brackets tend to spend a greater total amount on alcohol (Abdel-Ghany and Siver 1998). Social problems arising from alcoholism are serious by the pathological changes in the brain and the intoxication effects of alcohol such as confusion, disorientation and hallucination (McGrath, 1999) Alcohol abuse is associated with an increased risk of committing criminal offences, including child abuse, domestic violence, rape, burglary, assault and even death.

\section{Materials and Methods}

\subsection{Research Setting}

The study was carried out in the Agogo Hospital, Substance Abuse Unit at Agogo in the Asante Akyem North Districtwithin Ashanti Region of Ghana.The participants for this study were youth ageing between 18-30 years who attended the substance abuse clinic at Agogo Hospital which also serve as the district hospital for the Asante Akyem North District. They were recruited from October, 2015 to January, 2016. The total attendance from the beginning of the year till December, 2015 was 421, comprising both male and female service users.

\subsection{Study Design}

To achieve the objective of this study, a descriptive qualitative approach was employed. Such a study basically provides in-depth knowledge that is holistic, incorporating contextual influences. (Larrabee, 2009). As such it is the most suitable approach to unearth the experiences of the youth regarding factors that influence alcoholism. 


\section{International Journal of Science and Research (IJSR) \\ ISSN (Online): 2319-7064 \\ Index Copernicus Value (2013): 6.14 | Impact Factor (2014): 5.611}

\subsection{Sampling Techniques and Sample Size}

A purposive sampling technique was used to select participants. As the study sets out to explore psychosocial factors that influence youth alcoholism, the following inclusion and exclusion criteria was used to purposively select the participants. The participant;

- Must be a youth who has experienced alcohol abuse and has attended the substance abuse clinic for the last six months,

- Must be resident in the Agogo Community.

- Must be between the ages of 18-30 years

- Must be willingand ready to be interviewed.

This selection criterion was made known to the health professionals so they could assist in identifying the participants. Selection of participants was done on Tuesdays and Fridays which were the clinic days. A number of visits were done on these weekly clinic days until the required sample size was obtained. On each visit, the researchers identified some potential participants. Upon identification, the purpose of the study was explained to the participant and an information sheet made available to the participant for further reading. A total number of 12 youth participated in this study. Each participant was given the opportunity to choose a suitable venue for the interview. All twelve (12) participants indicated that they wanted to be interviewed in their homes and so researchers collected addresses and phone numbers of all the participants of those who owned phones for ease of contact and arranged to interview them at their various homes.

\subsection{Data Gathering Procedure}

A semi-structured interview guide was used to collect indepth information from each participant. These interviews were conducted personally by the researcher. All participants signed a consent form before the commencement of the interviews. Those respondents who could not sign were provided a stamp pad to thumb print. The interviews were audio taped. Each participant's demographic data was collected along with the interview data. Semi-structured interviews permit participants to respond freely to questions and also enable the researcher to get participants to describe and explain situations in a way that provides rich descriptive data. The questions posed by the researchers were based on psychosocial factors influencing youth alcoholism. Participants were encouraged to express themselves freely on all questions raised. Each interview session with a participant lasted between 25 to 40 minutes, whiles the data gathering was conducted within a period of two months. Each audio taped interview was transcribed after each session and the transcribed data reviewed to gain a proper understanding of each respondent's experiences. The transcribed data were later complemented with field notes. The audio taped interviews were transcribed verbatim in to a note book and later typed. Labels were used to identify various participants on the transcribed data. These labels were „P1 $1^{\text {ce }}$ which stands for participant 1, then P2 for participant 2 up to P12. Participants were assured of maximum confidentiality.

\subsection{Pretesting of interview guide}

To eliminate doubt and errors, the interview guide was pretested on three youth by the researcher. These youth did not form part of the main study. Pre-testing was also done to determine whether questions were clear, unambiguous and can be understood by the participants.

\subsection{Data Analysis}

Content analysis was used to analyse the data after the interview responses were transcribed verbatim into English by the researchers. The first level of analysis included coding which involved identifying words, phrases and paragraphs within the data and assigned a label to apportion the data to give it meaning. Initial lists of codes were prepared to label the themes emerging from the data. The codes in the list were revised and grouped together into larger thematic areas. In the search for core meanings and essence, researcher also paid attention to non-verbal communications but eliminated redundant information in participantse responses.

\section{Results \& Discussion}

Participants were interviewed on psychosocial factors influencing youth alcoholism. Results included youth unemployment and poverty, peer pressure,absence of leisure and boredom, inadequate knowledge of effects of alcoholism, absence of youth alcoholics support group, all contributing to youth alcoholism.

\section{Youth unemployment and poverty}

When participants were interviewed on unemployment, poverty and alcoholism, almost all participants acknowledged that unemployment and poverty have serious effect on alcohol abuse. This was because majority of the participants were unemployed. One of the participants said; "I feel hopeless for doing nothing no job no money so the little I get from friends I use it to drink." Others felt having no work is a very difficult situation hence they take to alcohol to while away the time. A participant said; "if I don't have anything to do I would drink, I wouldn't be drinking if I have something doing, would I?"

Although few participants (three) did not agree to unemployment as a factor influencing alcohol abuse, nonetheless majority attributed unemployment as a major factor for alcohol abuse.This result from the research is in line with first from psychological perspective; the financial challenges associated with unemployment could increase tension, anxiety, and family discord, thus leading to increase alcohol use (Catalano et al 2011)

One of the participant commented ,I know alcoholism is bad for my health but withno job, no support and no money, as far as I remain poor I will continue to drink, that"s my only joy left in this world, when I take in alcohol I feel relieved and happy" This was in line with UYDEL (2008), and Holder, et al (2007) as they indicated that there is a strong relationship between alcoholism and poverty. They noted that people drink because they are poor and they are poor because they drink. Alcohol is therefore both a cause and 


\section{International Journal of Science and Research (IJSR) ISSN (Online): 2319-7064 \\ Index Copernicus Value (2013): 6.14 | Impact Factor (2014): 5.611}

consequences of poverty as people drink to forget about misery of poverty.

Another study by Nedeljkovic (2014) has similar findings that youth unemployment is associated with increase in drug and alcohol use as well as higher levels of crime among young people. Similar research by Arkes 2007; Dee, 2001; confirmed the findings of this research, that unemployment results in greater leisure, which might encourage social drinking among the youth.

\section{Peer pressure}

Almost all participants agreed that peer pressure was a major factor influencing youth alcoholism. This was so because the youth tried to be accepted in their groups. For the fear of fall out within the group and recognition the youth will do anything to be accepted.

With regards to peer pressure,some participants made the following remarks:

"I was introduced to substance abuse, not only alcohol by my friends, because they were all doing it, and I needed to take some substance to be accepted in the group"

"Initially my friends and I were drinking for fun but I couldn "t stop drinking after sometime"

"I could only be part of the group if I learn to join them in drinking alcohol"

"I felt bad for not drinking with my group so finally I had to join them in the drinking spree"

One participant said "You can't say no if you are with them (friends)

This was in line with Borsari and Carey (2001) they indicated that peer influence is exerted directly, for example overt drink offers or urges to drink and indirectly, modeling perceived social norms. Donavan et al (2007) on the other hand found that it was friend's alcohol use and not the alcohol use of the larger friendship group that predicted initiation of alcohol use among $6^{\text {th }}, 8^{\text {th }}$, and $10^{\text {th }}$ grade students. Nevertheless in support to the current research, Crosnoe, eMullar\& Frank, (2004) stated that a more peerorientated lifestyle is strongly associated with alcohol use.

\section{Absence of leisure and Boredom \\ The reaction of most of the participants indicated that boredom was another factor influencing youth alcoholism. One participant said "there are no social activities and no recreational centres to go to socialize so the only thing is to go and drink with friends",}

While another said "when I feel bored I go on to drink to make myself happy and active". Another said "it"s too boring here",

The reactions of these two participants indicated that they were hooked to alcoholism because of boredom and absence of recreational activities in the community.

This confirms the findings of UYDEL (2008) that young people like taking alcohol and drugs to ,kill boredom ${ }^{\text {ee }}$ feel high, relieve stress, relax, and prove their maturity, for adventure s sake and to go through periods of cold weather.
Peterson, (2003) echoed that too much money, boredom and stress can lead to substance abuse. Complimenting all of the above, the National Center on Addiction and Substance Abuse (CASA) at Columbia University (2003)indicates thatmore than half (52\%) of youth are at risk for alcohol and substance abuse if they have any one of three risk factors; frequent boredom, stress and too much spending money.

\section{Inadequate knowledge of effects of alcoholism}

The results from the study showed that the youth had limited knowledge on the adverse effects of alcohol consumption, in line with a study by the European Alcohol Policy Alliance (2011), participants were mostly aware of short term risks such as road accidents, comas or unwanted sex. However, very few had any knowledge about the different conditions caused by alcohol. Participants were surprised by the link between alcohol and breast cancer or brain damage and many showed a genuine interest in being informed about these issues.

The study also revealed that most of the youth in the community have not had any education on the prevention of alcoholism. There is no resource or rehabilitation centres for those youth who want to abstain. Some participants said ,they wish to have stopped drinking but nowhere to turn to for help. Anotherparticipant said" there should be some education for me to abstain from alcohol abuse". Others saidthey have not had any education on the prevention of alcoholism in their area. One participant said "even at the Substance Abuse centre no proper education is given because of pressure of work on the minimum staff. This indicated that inadequate knowledge of effects of alcohol on the prevention of alcoholism among the youth is also one of the factors that influencing the youth to take in alcohol.

\section{Absence of youth alcoholics support group}

Most of the participants the participants recommended support groups to deal with alcoholism. One participant said "having youth alcoholics support group will help me to reduce the feeling of isolation" another one said "if I can get somewhere to turn to for help, I can deal with my fear of hopelessness"

According to HelpGuide.org, absence of youth alcoholics group contributed to youth alcoholism, as there were no such groups to help and assist the youth on alcoholism. It went on to indicate that groups are very helpful, not only maintain sobriety, but also as a safe place to get support and discuss issues.

\section{Conclusion}

This study explored psychosocialfactors influencing youth alcoholism at Agogo, Ghana,using a qualitative approach where in-depth interview techniques were employed.12 youth from the Substance Abuse Unit at Agogo Hospital were interviewed. Results; included peer pressure, youth unemployment and poverty, inadequate knowledge of the effect of alcoholism, absence of youth alcoholics support group, absence of leisure and boredom. Recommendations based on the findings included;massive education on effects of alcoholism in the media, hospitals and homes by Ministry of Health (MOH), Ghana Health Service (GHS) and health professionals; making clear the position of $\mathrm{MOH}$ on policies 


\section{International Journal of Science and Research (IJSR) \\ ISSN (Online): 2319-7064 \\ Index Copernicus Value (2013): 6.14 | Impact Factor (2014): 5.611}

on the risk and the dangers that pose to the youth in Ghana.Hospitals to create peer counseling unit tomanage peer pressures. Metropolitan, Municipal and District Assemblies to create some form of employment through youth training schemes and leisure centres to deal with boredom and youth unemployment.The government should come out with policies and programmes to support the youth to manage poverty. Finally, a strong rehabilitation and counselingcentres should also be established by the government and other non-governmental organisations to manage alcoholism.Thus, in conclusion alcoholism among the youth of Agogo and for that matter the Ghanaian youth requires a concerted efforts from all levels of the Ghanaian society both government and non- governmental organizations to assist the youth to deal with this canker.

\section{Future Scope}

The researcher with other members at the Department of Nursing would like to conduct a research on socio-economic factors influencing female alcoholism in greater Accra, using a quantitative methodology with participants over one thousands

\section{Acknowledgement}

The researcher is grateful to staff and all respondents at the Agogo Presbyterian Hospital who assisted and took part in this study.

\section{References}

[1] Abdel- Ghany, M .and J.L Silver (1998) "Economic and Demographic Determinants of Canadian Households use of and spending on Alcohol "Family and Consumer Sciences ResearchAmerican Journal of Public Health.

[2] Al-Haqwi, A.I. (2010). Perception among medical students in Riyadh, Saudi Arabia, regarding alcohol and substance abuse in the community: across-sectional survey. Substance Abuse Treatment, Prevention \& Policy, 51-56. Doi:10.1186/1747-597X-5-2

[3] Al Marri, T.K., \&Oei, T.S. (2009). Alcohol and substance use in the Arabian Gulf region: A review. International Journal of Psychology, 44(3), 222-233. doi:10.1080/00207590801888752

[4] Arkes, Jeremy. (2007) Does the economy affect teenage substance use? Health Economics; PubMed: 16960850 Vol. 16(No. 1):19-36.

[5] Beck, K .H, Thombs, D.L and Summons, T.G (1993).The social context of drinking scales: Construct Validation and relationship to indicants of abuse in an adolescent population Addictive behavior.

[6] BenegalV, Borges G, Casswell S, et al. (2007) Alcohol and injury in emergency departments: summary of the report from the WHO collaborative study on alcohol and Injuries 2007. Available from: http://www.who.int/substance_abuse/publications/alcoh ol_injurysummary

[7] Borsari, KB Carey.(2001) Journal of Substance Abuse, 13,391-424

[8] Catalano Ralph A, Goldman-Mellor Sidra J, Saxton Katherine, Margerison-Zilko Claire E,
SubbaramanMeenakshi, LeWinnKaja, Anderson Elizabeth. (2011) The health effects of economic decline. Annual Review of Public Health; 32:431-450.

[9] Chassin, L.; Curran, P.S.; Hussong, A.M.; and Colder, C.R (1996). The relation of parent alcoholism to adolescent substance use: A longitudinal follow up study.

[10] Crosnoe, eMullar\& Frank, (2004).Alcohol use among in Europe.Environmental Research and Preventive Action.

[11] Dee, Thomas S. (2001) Alcohol abuse and economic conditions: Evidence from repeated cross-sections of individual level data. Health Economics; PubMed: 11288191, Vol. 10:257-270.

[12] Donovan, J.E. (2004). Adolescent alcohol initiation: a review of psychosocial risk factors. The Journal of Adolescent Health, official publication of the society for adolescent medicine, 35(6), 7-18

[13] Duncan, T.E , S.C .Duncan , et al (1998) Latent variable modeling of longitudinal and multilevel Alcohol use Date ,'Journal of studies on alcohol.

[14] Brundtland, G,H (2001). WHO European Ministerial Conference on Drug Abuse Resistance Education.

[15]European Alcohol Policy Alliance (2011).Study exposes young people's lack of knowledge about the long-term consequences of alcohol consumption. EuroCare.

[16] Finger, B., Kachadourian, L.K., Molnar, D.S., Eiden, R.D., Edwards, E.P., \& Leonard, K.E. (2010). Alcoholism, associated risk factors, and harsh parenting among fathers: Examining the role of marital aggression. Addictive behaviors, 35(6), 541-548

[17] Freeman, M. \&Parry,C. (2006). Alcohol use literature review. The Soul City Institute for Health \& Development Communication.

[18] Harker, R (2012). Statistic on Alcohol, London: House of Commons Library, pp. 3-6.

[19] Help Guide.Org. (Anonymous). Self-Help Groups for drug addiction

[20] Holder, Harold D. (2007). What we learn from a reduction in retail prices: lessons from Finland Addiction. Vol. 102, isue3, pp346-347.

[21] Hughes, K,Mackintosh, Wheeler,C, Watson,J and Inglis,J ,A.M Hastings(1997) Young people, alcohol and designer drinks .Quantitative and qualitative study British medical Journal.

[22]Hussong, A.M and L.Chassin(1997). Substance use Initiation Among adolescent children of Alcoholics

[23] Langdana, Farrokh .K (2009) Macroeconomic policy Demystifying monetary and fiscal policy

[24]Laurie. M (2001).The dilemma of helping, making aid fair and effective.Academic Press.NY, pp.27-59

[25] Mayor, S. (2001). Alcohol and drug misuse sweeping the world, says WHO. British Medical Journal, 322:7284.

[26] McGrath, C.E.; Watson, A.L. and Chassin, (1999) Academic achievement in adolescent children of alcoholics.

[27] Myadze, T, I., and Rwomire, A. (2014)Alcoholism in Africa during the late twentieth century: A sociocultural perspective. International Journal of Business and Social Science Vol. 5 No. 2 


\section{International Journal of Science and Research (IJSR) \\ ISSN (Online): 2319-7064}

Index Copernicus Value (2013): 6.14 | Impact Factor (2014): 5.611

[28] National Center on Addiction and Substance Abuse (CASA) at Columbia University (2003) Three factors threaten teens

[29] Nedeljkovic V., (2004). Consequence of high youth unemployment, bridging Europe.

[30] Peterson S. Karen (2003). Three factors threaten teens. USA Today.

[31] World Bank on Alcohol and Poverty.(2007). Alcohol, drugs and development.FORUT.

[32]WHO, (2011).Global status report on alcohol and health.

[33] WHO. (2013) Status report on alcohol and health in 35 European countries

[34] White, K Jackson.(2005) Alcohol research and health, 28, 4, 182-191

[35](UYDEL) Uganda Youth Development Link (2008).State of alcohol abuse in Uganda.

\section{Author Profile}

Samuel Owusu-Akyem is currently the Head of Department, Nursing Presbyterian University College, Ghana. He holds a PhD in Health Education. He is a lecturer- practitioner in mental health with over twelve experience both in Ghana and the United Kingdom. 